\title{
Evaluating management zone maps for variable rate fungicide application and selective harvest
}

\author{
Rebecca L Whetton ${ }^{\mathrm{a}}$, Toby W Waine ${ }^{\mathrm{a}}$, and Abdul M Mouazen ${ }^{\mathrm{a}, \mathrm{b} *}$ \\ ${ }^{a}$ Cranfield Soil and AgriFood Institute, Cranfield University, Bedfordshire MK43 0AL, UK. \\ ${ }^{\mathrm{b}}$ Department of Soil Management, Ghent University, Coupure 653, 9000 Gent, Belgium. \\ * E-mail of corresponding author: Abdul.Mouazen@UGent.be
}

\begin{abstract}
Currently the majority of crop protection approaches are based on homogeneous rate fungicide application (HRFA) over the entire field area. With the increasing pressures on fungicide applications, associated with increased environmental impact and cost, an alternative approach based on variable rate fungicide application (VRFA) and selective harvest (SH) is needed. This study was undertaken to evaluate the economic viability of adopting VRSA and SH in winter wheat and the environmental benefit in terms of chemical reduction is also discussed. High resolution data of crop canopy properties, yellow rust, fusarium head blight (FHB), soil properties and yield were subjected to $k$-means cluster analysis to develop management zone (MZ) maps for one field in Bedfordshire, UK. Virtual cost-benefit analysis for VRFA was performed on three fungicide application timings, namely, T1 and T2 focused on yellow rust, and $\mathrm{T} 3$ focused on FHB. Cost-benefit analysis was also applied to SH, which assumed different selling prices between healthy and grain downgraded due to mycotoxin infection. Results showed that in this study VRFA allowed for fungicide reductions of $22.24 \%$ at $\mathrm{T} 1$ and $\mathrm{T} 2$ and $25.93 \%$ at T3 when compared to HRFA. SH reduced the risk of market rejection due to low quality and high mycotoxin content. Gross profit of combining SH and VRFA was $£ 83.35$ per hectare per year, divided into SH $£ 48.04 \mathrm{ha}^{-1}$, and VRFA $£ 8.8 \mathrm{ha}^{-1}$ for T1 and T2 and $£ 17.7 \mathrm{ha}^{-}$

${ }^{1}$ for T3. Total profit when considering soil and crop scanning costs would be $£ 66.85 \mathrm{ha}^{-1}$ per
\end{abstract}


year, which is roughly equivalent to $€ 80$ or $\$ 90 \mathrm{ha}^{-1}$ per year. This study was restricted to a single field but demonstrates the potential of fungicide reductions and economic viability of this $\mathrm{MZ}$ concept.

\section{Keywords}

Cereal crop disease; Management zones; Cost-benefit analysis; Selective harvest; Variable rate fungicide application

\section{Introduction}

High crop yields would ideally be achieved with minimal environment impact. Conventional agricultural practice has led to increased crop yields, but depends on the unsustainable management of external inputs, posing severe environmental problems (Pimentel et al., 1995; Hole et al., 2005). Considerable yield losses occur due to crop diseases, requiring the development of sustainable approaches to crop disease management. Variable rate management of farm external inputs is a potential approach to achieve this. Site-specific management requires high resolution data on all relevant factors. High resolution data collection for specific diseases, crop canopy, and soil properties is possible with the use of online crop and soil sensors (Kuang et al., 2012; Kuang and Mouazen, 2013; Whetton et al., 2018a). Fusing these different layers of information allows for the creation of management zones (MZ). This study will focus on and explore the potential use of these MZ for variable rate fungicide application (VRFA, where the rate of fungicide can be varied in response to requirement), and selective harvest ( $\mathrm{SH}$, where grain can be harvested separately in areas of high and low quality).

Yellow rust is a foliar fungal disease that is linked with a long history of yield loss. Yield loss is mostly attributed to a reduction in the number of grains per ear, and the weight of individual 
grains (Herrera-Foessel et al., 2006). Across the globe, yield losses due to yellow rust are reported to be between 10 and $70 \%$ (Chen, 2005), with susceptible varieties often being $>50 \%$ (Safavi, 2015). Historically, Doodson et al. (1964) reported yield losses of 64.5\% in individual infected plants, whilst Doling and Doodson (1968) attributed yield loss reductions of up to $30 \%$ to the cultivation of resistant spring and winter wheat varieties.

Fusarium head blight (FHB) is a sporadic ear disease, with level of infection varying across regions and years (Jelinek et al., 1989). FHB can result in yield losses, economic losses (direct and indirect) and negative influences on human and animal health (Paul et al., 2005). The direct economic loss is attributed to reduced grain quantity and size, while indirect loss is due to reduced quality, and mycotoxin contamination (a secondary metabolite of the fusarium mould), associated with market rejection or downgrading of grain (Parry et al., 1995). The downgrading of grain can occur if a portion of the harvested grain is of lower quality, this can reduce the overall quality or cause the harvested grain to surpass the mycotoxin health limits. With the increased awareness of food security, and the knowledge that one third of food is currently lost or wasted, innovative studies are needed to maximise yields and quality of yield reaching the market (Gustavsson et al., 2011). It is estimated that without the use of crop protectants and fungicides about $50 \%$ of wheat yield can be lost due to pests (Oerke, 2006). To generate similar yield levels, an expansion of the extent of arable land will be required and combined with inefficient application of external inputs, this may lead to increased levels of greenhouse gas (GHG) emissions (Mahmuti et al., 2009; Berry et al., 2010; Burney et al., 2010; Carlton et al., 2010). Use of fungicides for disease control on wheat, barley and oilseed rape is estimated to save emissions in excess of 1.5 Mt CO2-e in each cropping season (Hughes et al., 2011), while reductions in external inputs is also linked to decreased emissions (Lin et al., 2011). 
Soil characteristics affect the crop growth and yield, e.g. more fertile soil leads to stronger and more resistive plants if plant density is controlled (Sylvester-Bradley and Kindred, 2009). Microclimate conditions also affect crop growth and disease spread with a greater occurrence of fungal diseases observed in denser canopies, but a conclusive regression relationship through multiple years and fields has not been found, potentially due to the confounding effects of weather (Rozalski et al., 1998). An essential step towards site specific plant protection is information about crop disease in the field, collected at high sampling resolution. However, information on crop disease alone is not sufficient for an integrated decision support system, due to the influence of other factors e.g., relevant soil properties, microclimate conditions and crop canopy characteristics (Sylvester-Bradley and Kindred, 2009). To our best knowledge, no assessments exist examining the environmental and economic benefits of VRFA for yellow rust and $\mathrm{FHB}$, and $\mathrm{SH}$ based on fusion of high sampling resolution data, of soil characteristics, crop growth and diseases, and microclimate conditions.

The aim of this paper is to apply a multi-sensor and data fusion approach for the delineation of MZ maps for VRFA and SH. It will evaluate whether these approaches could have potential economic benefits. This study focuses on the potential economic benefits, using a virtual costbenefit analysis, of heterogeneous fungicide applications and selective harvest based on high sample data, compared to a conventional practice.

\section{Materials and methods}

\subsection{Field site}

One study field of 10.8 ha with cereal crop production was selected for this study. It is located at Duck End Farm, a commercial family farm in Wilstead, Bedfordshire, UK $\left(52^{\circ} 05^{\prime} 46.3^{\prime \prime} \mathrm{N}\right.$ $\left.0^{\circ} 26^{\prime} 41.4^{\prime \prime} \mathrm{W}\right)$, with an average annual rainfall of $598 \mathrm{~mm}$. The northern part of the field is a clay soil, whereas the southern part is a sandy clay soil. The farmer uses a 3-year crop rotation 
of barley, wheat and oil seed rape. The experiment was carried out in 2015 during the winter wheat rotation. Yellow rust and FHB were observed in the field. Measurement dates of soil, crop canopy, diseases, micro-climate conditions, and yield in relation to growth stages are shown in Table 1. Detailed information about the collection of each dataset is further described below.

Table 1: Date of different measurement as related to crop growth stages according to the BBCH scale (Lancahsire et al., 1991).

\begin{tabular}{lll}
\hline Parameter & Date of measurement & Growth stage \\
\hline Yield & September, 2015 & NA \\
NDVI and LAI & May, 2015 & 43 \\
Soil properties (MC, TN, & September, 2014 & NA \\
OC, CEC) & \\
Yellow rust early & May, 2015 & 43 \\
Yellow rust late & July, 2015 & 70 \\
Fusarium head blight & July, 2015 & 70 \\
Canopy data (humidity, & May, 2015 & 43 \\
temperature) & & \\
\hline
\end{tabular}

NDVI is normalised difference vegetation index; LAI is leaf area index; MC is moisture content; TN: is total nitrogen; CEC is cation exchange capacity; OC is organic carbon 


\subsection{Disease and canopy data collection}

A push broom hyperspectral imager (spectrograph) (HS spectral camera PS model from Gilden Photonics Ltd., UK) using a spectral range of 400 and $750 \mathrm{~nm}$ was used. The imager along with a halogen light source were mounted on a tractor, by means of a metal frame for on-line measurement of yellow rust and FHB. The optimal configurations include an integration time of $50 \mathrm{~ms}$, a camera height of $0.3 \mathrm{~m}$ and light height and distance of $1.2 \mathrm{~m}$ and a camera angle of $10^{\circ}$. Measurement was carried out at a forward travel speed of approximately $4 \mathrm{~km} \mathrm{~h}^{-1}$, and line images were captured at $1 \mathrm{sec}$ frequency, which is subsequently logged and geo-located with a sub-meter accuracy, using a differential global positioning system (DGPS) (EZ-Guide 250, Trimble, California, USA). At 5 locations per hectare ground truth plots were selected (Figure1), where manual disease assessment and recognition of yellow rust and FHB were made ( 0 for no infection, 1 for less than 5\% infected heads (FHB) or leaf area (yellow rust), 2 for up to $10 \%, 3$ for up to $30 \%, 4$ for up to $50 \%$, and 5 being a heavy infection of over $50 \%$ ) and applied to calibration models. Whilst the NIR is a key spectral region for detecting early disease symptoms, successful models for crop disease detection have been built using the visual spectrum, highlighting the significance of the $500 \mathrm{~nm}, 600 \mathrm{~nm}$, and $650 \mathrm{~nm}$ wavebands (Sasaki et al., 1999; Thomas et al., 2017). The models utilised in this study were classed as a good accuracy 0.78 and $0.82 \mathrm{R}^{2}$ for the detection of established yellow rust and FHB, respectively. The methodologies and models for application of the hyperspectral imager and crop disease detection was utilised from our previous (Whetton et al., 2017, 2018a and 2018b).

At the same 60 ground truth locations, data of leaf area index (LAI) was collected with use of a Sunscan (V1, Delta-T devices, Cambridge, UK) sensor, while air humidity and temperature were measured with a hand-held device (Testo 610, Hampshire, UK), positioning the sensor just under the flag leaf. Yield was measured with on-board yield sensor of the farmer's combine 
harvester (New Holland, CX8070 model) and normalised difference vegetation index (NDVI) was measured with an online Crop Circle sensor (Crop Circle ACS 470, Holland Scientific, Lincoln, NE USA).

\subsection{On-line soil measurement}

An on-line visible and near infrared (vis-NIR) spectroscopy sensor (Mouazen, 2006) was used to measure soil total nitrogen $(\mathrm{TN})$, organic carbon $(\mathrm{OC})$, moisture content $(\mathrm{MC})$ and cation exchange capacity (CEC). It consists of a mobile, fibre type, AgroSpec visible and near infrared (vis-NIR) spectrophotometer (tec5 Technology for Spectroscopy, Germany) with a measurement range of 305-2200 nm, and a differential global positioning system (DGPS) (EZGuide 250, Trimble, USA) to record the position of the on-line measured spectra with submetre accuracy. The spectrophotometer was linked with an optical probe by means of two optical fibres. The optical probe was attached to the underside of a subsoiler, which penetrated the soil opening a smooth trench. The probe was illuminated by a $20 \mathrm{w}$ light source and collected diffuse reflected spectra at $1 \mathrm{sec}$ frequency. A detailed description of the system can be found in Kuang and Mouazen (2013). On-line measurement was carried out in 2014, after the harvest of the previous crop at parallel transects approximately $10 \mathrm{~m}$ apart and at $2 \mathrm{~km}$ forward speed, at a sensor depth of $15 \mathrm{~cm}$.

\subsection{Spectral modelling of disease and soil properties}

The pre-processing of the soil and canopy spectral data was carried out following an approach outlined in Mouazen et al. (2006). The first step was to remove the noisy wavelengths at the two far edges of the soil spectra, as this had already been clipped from the canopy spectra. The spectra then underwent averaging of neighbouring wavebands, maximum normalisation, first 
derivative and smoothing, successively. All spectra pre-processing was carried out using Unscrambler 10 software (Camo Inc.; Oslo, Norway).

The hyperspectral imager data set was randomly divided into two sets of $70 \%$ and $30 \%$, representing the calibration and validation data sets, respectively. The pre-processed canopy spectra and manual assessments of disease were subjected to partial least squares regression (PLSR) analysis with leave-one-out full-cross validation using the calibration set (70\%). PLSR analyses were carried out using Unscrambler 10 software (Camo Inc.; Oslo, Norway). The model's performance was evaluated using the on-line validation set $(30 \%)$. The prediction results of these models are shown in Table 2. More detailed information about the calibration and validation of the FHB and yellow rust models can be found in Whetton et al. (2018a and 2018b). The same approach was used for the calibration and validation of models to predict soil properties (e.g., MC, OC, TN and CEC). More detailed information about the calibration and validation of these models can be found in Kuang and Mouazen (2013) for TN, OC and MC and Marin-González et al. (2013) for CEC (Table 2).

Since the canopy properties LAI, humidity and temperature were measured only at 60 locations (shown in Figure 1), these limited data set was used for further analysis. However, a much larger number of data points was obtained of the on-line predicted crop yellow rust and FHB, on-line predicted TN, OC, MC and CEC and measured NDVI and yield. 


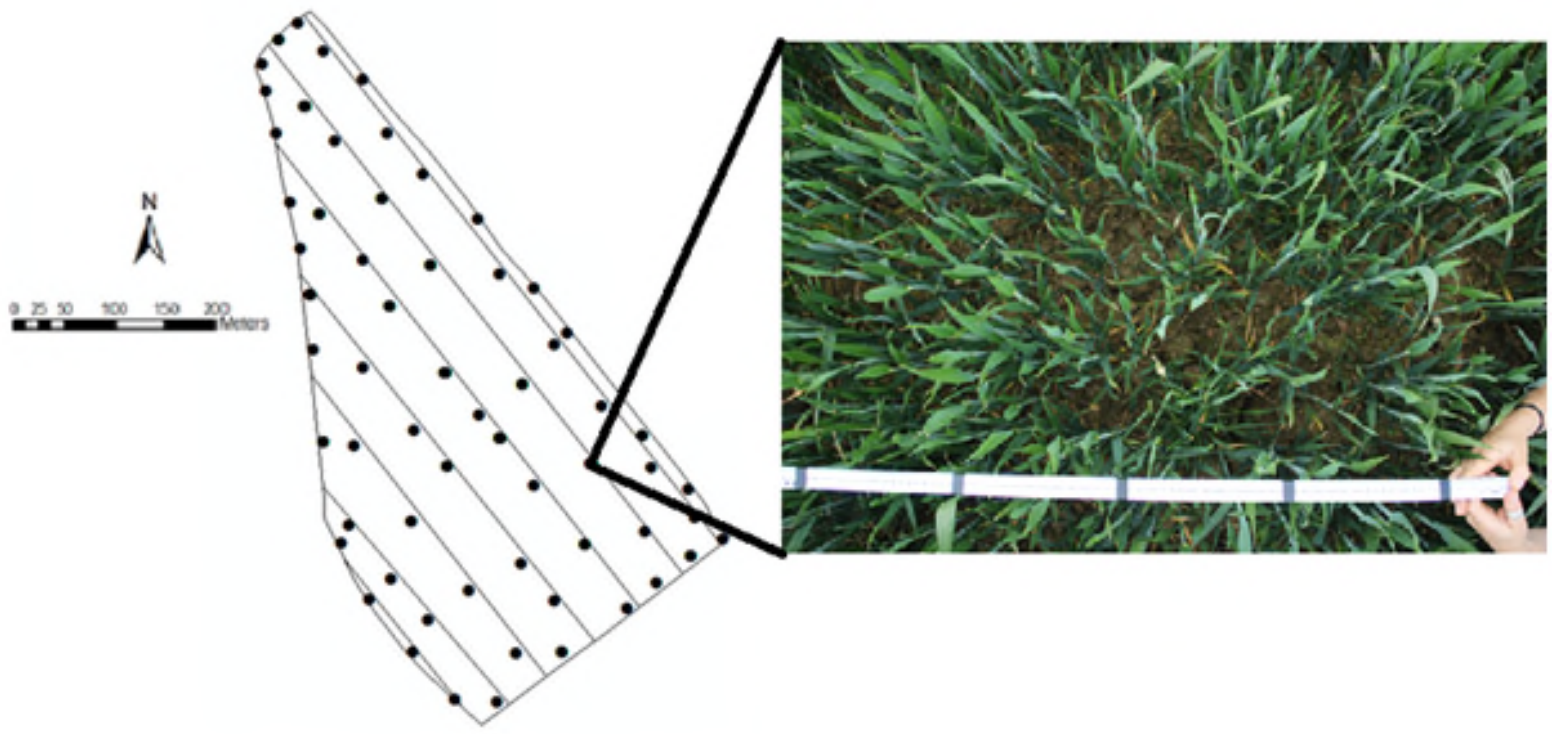

Figure 1: Map of the experimental field where ground sample locations ( 5 per hectare, $n=60$ ) are shown.

\subsection{Mapping}

Maps for each of the properties were developed using ArcGIS 10 software (ESRI, California, USA). The first step in the development of maps was the creation of semi-variograms in Rstudio (RStudio, Boston, MA), which are presented in Table 2. After an optimal semivariogram (smallest sum of square error) was established for a given property, kriging was applied to develop a full point map using ArcGIS 10 software (ESRI, California, USA). Different number of data points was considered in the semi-variogram development and kriging, hence, the resolution of maps differs, although the best fit was found with spherical semi-variograms for all properties investigated. 
Table 2: Properties of the spherical semi-variogram obtained for yellow rust early (YR early) and late (YR late) scans, fusarium head blight (FHB), soil moisture content (MC), organic carbon (OC), total nitrogen (TN), cation exchange capacity (CEC), leaf area index (LAI) and normalised difference vegetation index (NDVI), crop humidity and temperature. Showing nugget $\left(\mathrm{c}_{0}\right)$, sill $(\mathrm{c})$, range $(\mathrm{r} \mathrm{m})$, proportion $(\mathrm{C} 0 / \mathrm{C} \%)$, and the sum of square error (SSE). The ratio of prediction deviation (RPD) values are presented for the spectral models of OC, TN, and MC, developed by Kuang and Mouazen (2013), CEC, developed by Marin-González et al . (2013), and FHB and YR, developed by Whetton et al. (2018b).

\begin{tabular}{lllllll}
\hline Property & $\mathbf{c 0}$ & $\mathbf{r}(\mathbf{m})$ & $\mathbf{c}$ & $\mathbf{c 0 / c}(\mathbf{\%})$ & SSE & RPD \\
\hline FHB & 0.11 & 97.02 & 0.89 & 8.02 & 3.32 & 2.27 \\
YR early & 0.00 & 78.34 & 0.001 & 9.00 & 2.56 & 2.50 \\
YR late & 0.01 & 92.57 & 0.04 & 2.93 & 1.53 & 2.50 \\
OC & 0.00 & 9.60 & 0.01 & 9.55 & 2.65 & 2.36 \\
TN & 0.00 & 23.04 & 0.01 & 3.00 & 12.46 & 1.85 \\
MC & 4.43 & 15.52 & 5.09 & 0.81 & 6.23 & 1.49 \\
CEC & 0.73 & 24.71 & 1.48 & 1.78 & 4.20 & 1.70 \\
NDVI & 0.061 & 4.45 & 0.21 & 2.6 & 2.15 & NA \\
Yield & 3.24 & 98.36 & 6.49 & 4.25 & 1.68 & NA \\
LAI & 1.08 & 68.04 & 2.07 & 1.9 & 3.06 & NA \\
Humidity & 0.17 & 102.96 & 1.07 & 6.19 & 0.57 & NA \\
Temperature & 0.1 & 83.09 & 1.06 & 10.05 & 0.51 & NA \\
\hline
\end{tabular}

$\mathrm{c}_{0}$ is nugget variance, $\mathrm{c}$ is sill, $\mathrm{r}$ is range, $\mathrm{c} 0 / \mathrm{c}$ is proportion, and $\mathrm{SSE}$ is sum of squared error. 


\subsection{Management zone maps}

Typically, there are up to four timings of fungicide application to control foliar diseases and ear diseases. Timing 0 (T0) is applied between growth stage 25 and 30 according to $\mathrm{BBCH}$ (Lancahsire et al., 1991). Fungicide application is usually preventative in historically problematic fields, or if early disease is observed. T1 (GS 31-33) and T2 (GS 37-39) are applied to keep the third, second and flag leaves healthy, as these heavily influence yield in wheat. The T3 application (GS 52-60) can also be an "ear wash", and is usually applied to preserve the quality of the grain. $\mathrm{T} 2$ is commonly considered the most crucial application and is the most frequently applied, due to the importance of maintaining flag leaf health. T1 is considered secondary in importance followed by T3 and then T0 (Clark, 2016).

The predicted soil properties and crop disease levels measured canopy and yield parameters and microclimate conditions were pulled into one matrix by means of a Statistica software (StatSoft inc., Oklahoma USA), before running $k$-means clustering. A $k$-means cluster is an unsupervised learning algorithm, which partitions multiple observations into a suitable number of clusters, and a data point is classified into a cluster point based on the cluster with the nearest mean (MacQueen, 1967), which allowed MZ based on multiple properties to be delineated, for VRFA and SH. The $k$-means cluster analyses were performed for the following applications to produce three different maps, with a different number of MZ, depending on variability of the input data used:

1) Selective harvest: In this case only the on-line predicated FHB and late yellow rust were included in the $k$-means clustering to produce a MZ map for $\mathrm{SH}$.

2) T1 and T2 variable fungicide applications: The $k$-means cluster analysis here aimed at producing MZ maps for VRFA at growth stages 31 to 39, applied as a foliar disease 
preventative. In this case, the predicted early yellow rust levels and soil properties (MC, OC, TN and CEC) and measured canopy properties (NDVI, LAI, canopy humidity and temperature) were included in the analysis.

3) T3 variable fungicide applications: The $k$-means cluster analysis produced a MZ map for the growth stage 52-60, where fungicides are usually applied to preserve the grain quality. Input data included the on-line predicted FHB and soil properties (MC, OC, TN, and CEC) and measured canopy properties (NDVI, LAI, canopy humidity and temperature).

\subsection{Cost-benefit analysis}

The following assumptions were made in this study for the cost-benefit analyses;

1) The cost of implementing the different sensing technologies was assumed to be $£ 10$ ha $^{-}$

${ }^{1}$ for soil data (commercial price of soil sensing in the UK) and $£ 6.5 \mathrm{ha}^{-1}$ for crop growth and diseases (comparable to cost of current commercial VR N recommendation price in the UK based on crop data only). It is assumed that soil sensing will be carried out in one operation with tillage, whereas crop sensing will be carried out in one operation with fertilisation.

2) FHB presence is directly linked to mycotoxin presence, which is in line with Paul et al. (2005), who reported a mean correlation of $\mathrm{R}^{2}$ of 0.73 between deoxynivalenol (DON) level and fusarium observed in 163 studies in the USA.

3) VRFAs would not reduce the efficiency of disease control obtained with homogeneous applications, an assumption supported by a practical note that reduced doses of fungicide should be applied in low disease pressure areas (FRAC, 2010) and vice versa. 
4) Wheat grain would be sold at a lower price due to fusarium contamination of mycotoxins. This assumption is supported by the European commission imposed upper limits of the DON mycotoxin in cereal grain for human consumption.

5) A uniform application of fungicide was proposed for the T0 growing stage, as it is usually a preventive treatment and at this early growth stage disease sensing would be difficult, as the canopy is sparse.

Two fungicides commonly used in disease control were selected for this study. Adexar (epoxicoazole) is suitable for the treatment of many fungal disease infections and is particularly common for FHB treatment. It is used at a maximum of 2 litres per hectare $\left(1 \mathrm{ha}^{-1}\right)$, with a maximum of 2 applications per annum for wheat in Europe. The current price (2017) is $£ 34$ per litre. Proline 275 (prothioconazole), is suitable for many fungal disease infections but particularly for treatment of yellow rust. It is applied at a maximum of $0.72 \mathrm{lha}^{-1}$ per dosage, with a max total of $2.161 \mathrm{ha}^{-1}$ per year for wheat treatment in Europe. The 2017 price is between $£ 52.5$ and $£ 59$ per litre ${ }^{1}$. The following two cost-benefit analyses were carried out for the VRFA and $\mathrm{SH}$;

1- The cost-benefit for the variable fungicide treatments (T1, T2 and T3) was applied using ArcGIS 10 software (ESRI, California, USA), by dividing the field area into high infection risk (HIR) and low infection risk (LIR) zones, taking into consideration the boom width relative to the position of tramlines. Zones of HIR were virtually subjected to a full application rate, whereas the LIR zones were given a 50\% application rate. For T3 the medium infection zones (MIF) were subjected to $75 \%$ dosage rate. All MZ were considered in the analysis, and the amount of fungicide per area was calculated. The overall applied amount of fungicide was then compared to that of a conventional full homogenous application (100\% application rate), and the potential savings or losses were calculated. 
2- The cost-benefit analysis for SH was calculated in a similar manner to that of VRFA using ArcGIS 10 software (ESRI, California, USA). MZ were classified into HIR and LIR. This was made by proposing separate harvest of the HIR (low quality) from that of the LIR (high quality) zones. All MZ were considered in the analysis, and their corresponding area were calculated, so as the average yield per zone could be calculated. The total prices of wheat grain obtained from Farmer's Weekly (FWI, 2016) were $£ 145$ and $£ 135$ per tonne, for the high-quality and low-quality yield, respectively. The SH was compared to the homogeneous harvest of the entire field-area, sold at the lower price of $£ 135$.

\section{Results and discussion}

\subsection{Spatial variability of different properties}

The analysis for semi-variogram of different soil and crop properties indicated that the best approximation can be achieved with spherical models, whose properties can be found in Table

2. The largest sum of square error is calculated for TN followed by MC. The small values of the proportion between the nugget (attributed to small sampling intervals, or measurement errors) to sill variation (less pairs of points separated by far distances) indicate the autocorrelation between different properties studied, because this proportion is an important parameter to quantify short-distance autocorrelation or the degree of spatial dependency for a variable (Cambardella et al., 1994; Chang et al., 2014). Cambardella et al. (1994) defined three categories of spatial dependency of high, moderate, and weak with ratios of less than $25 \%$, between $25 \%$ and $75 \%$, and greater than $75 \%$, respectively. Ranges of spatial dependency are wider than the sampling interval of on-line soil measurement $(10 \mathrm{~m})$, disease (Figure 2), LAI, humidity and NDVI (24 m) (Figure 3), and yield (12 m) (Figure 4), confirming the 
effectiveness of geostatistical analysis adopted in this study (Chang et al., 2014). The only exception is for the NDVI measurement (Table 2).

As a general observation, the crop was healthier towards the centre of the field. This was particularly evident in the early yellow rust map (Figure 2). This is an expected spatial pattern, as yellow rust and fusarium spores are both wind borne and can survive in soil and weeds occurring in the borders of a field, acting as a source of inoculum for the next cropping season (Jenkinson and Parry, 1994; Imathiu et al., 2013). Between the early and late scan of yellow rust, some small areas decreased in disease severity, which could be due to additional crop growth (from later tillers and secondary tillers) and regrowth of damaged crop (Livingston et al., 2016).

Field areas high in NDVI correlated with areas high in LAI (Figure 3). The central part of the field is of low LAI/NDVI, which coincides well with low concentrations of both FHB and early yellow rust spatial distribution pattern in the field. LAI/NDVI and temperature appear to have similar spatial distribution pattern, but of inverse magnitude. Areas of the field with a lower crop density will warm up and cool down faster than those with dense canopies (Dammer, 2003). Differences in a wheat field's canopy temperature could have an inter-canopy variation of up to $7.5^{\circ} \mathrm{C}$ (Dammer, 2003), a variation of $5.4^{\circ} \mathrm{C}$ (at canopy level) was recorded during the field scan in May. At the time of scanning the lower temperatures were found in denser canopies, highlighting the differences in microclimate through the field. The values of each property may vary throughout the growing season (i.e., moisture content and temperature may change significantly within a few hours). However, the pattern of spatial variability will persist for significantly longer. 


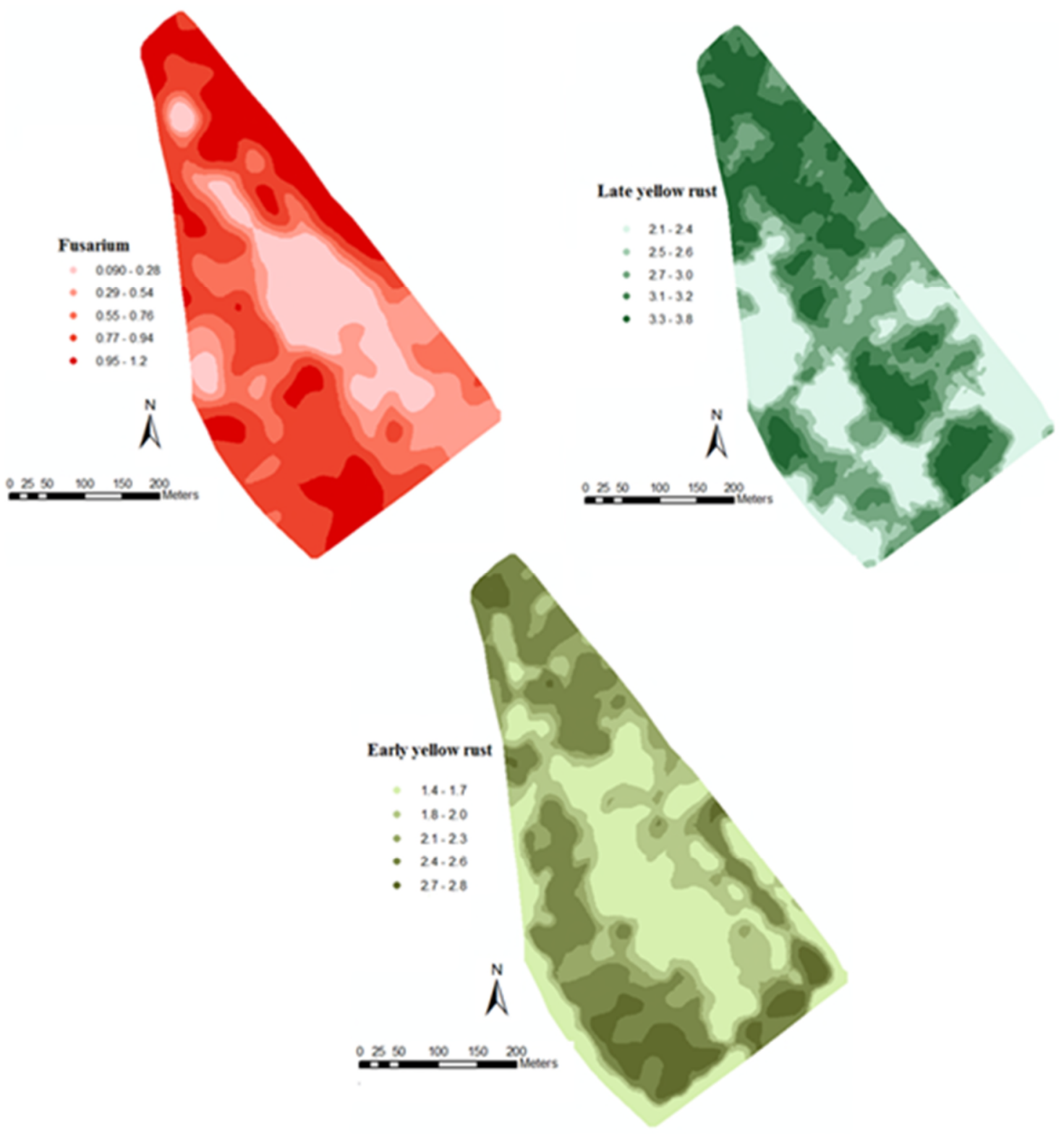

Figure 2: Disease severity; On-line predicted maps of fusarium head blight (FHB) measured at milk growth stage 72 (July 2015), early yellow rust measured at booting growth stage 43 (May 2015), and late yellow rust measured at milk growth stage 72 (July 2015). The disease is classified on a 0 to 5 scale, where 0 indicates low disease presence and 5 indicates high disease. 
A small spatial variability of the four on-line predicted soil properties (CEC, TN, MC and OC) was observed (data not shown), hence, might not have effect on crop diseases, an assumption to be tested further below. Clear spatial similarity between crop yield (Figure 4) and NDVI (figure 3) can be observed. The highest yield is recorded in the middle part of the field, which coincides with the NDVI map. This is in line with other studies, reporting that NDVI of previous years can be used as an indicator for yield in the following years (Mkhabela et al., 2011).

Both macro and micro nutrients have an impact on the severity of fungal diseases. Nutrient deficiency will increase the crop's vulnerability to specific diseases, (Huber, 1980; Engelhard, 1989; Graham and Webb, 1991; Agrios, 1997; Fageria and Baligar, 1997; Snoeijers et al., 2000; Dordas, 2009). Increases in nitrogen will increase the green area index, crop density and duration of the canopy (Stokes et al., 1997; Sylvester-Bradley and Kindred, 2009). This subsequently affects the microclimate of the crop and the efficacy of the disease control (Bryson et al., 1997). 

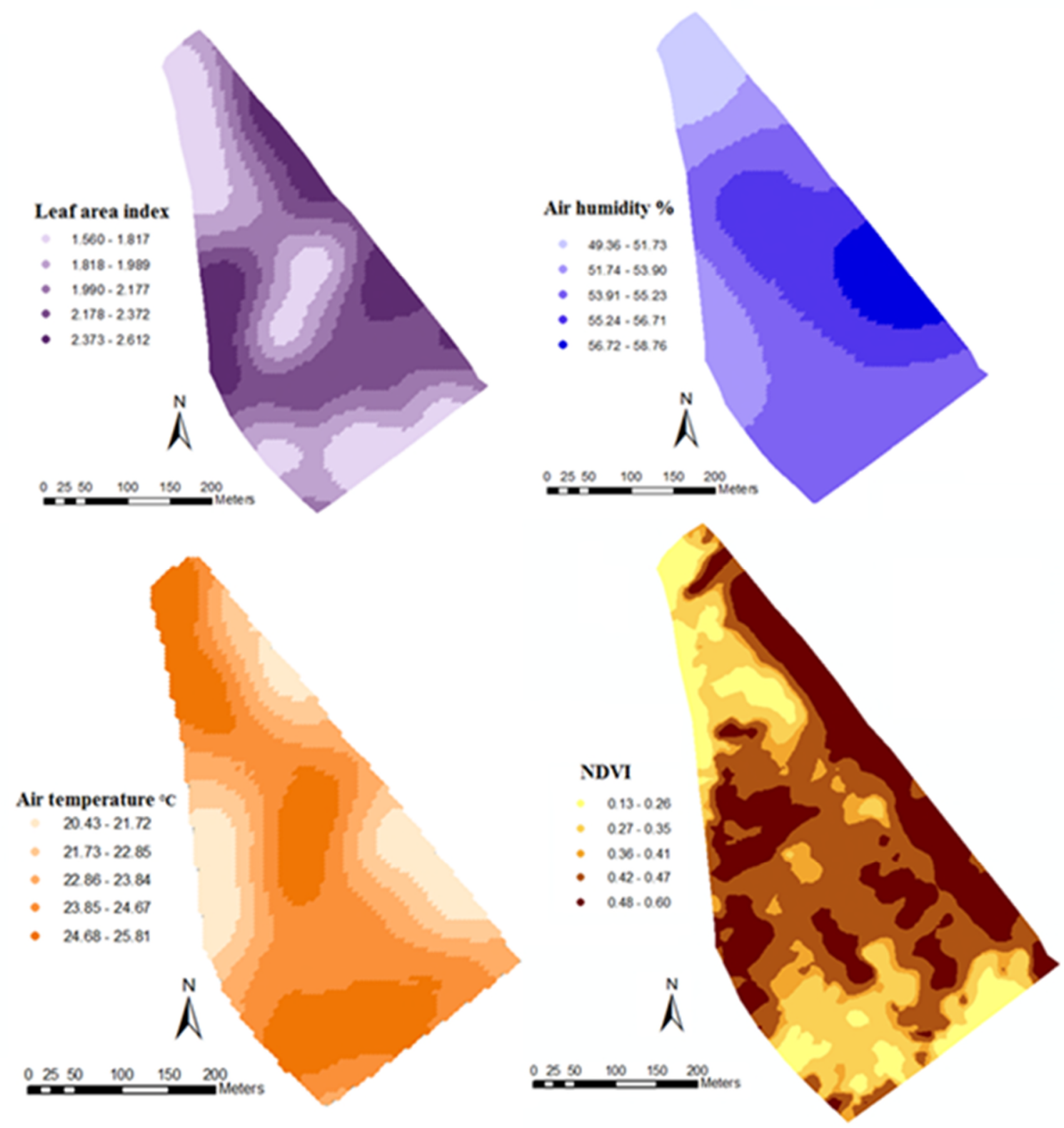

Figure 3: Properties attributed to the canopy; On-line measured normalised difference vegetation index (NDVI), along with the 60 samples based developed maps for leaf area index (LAI), canopy air temperature and humidity. These data were all collected at the booting growth stage 43, in May 2015. 


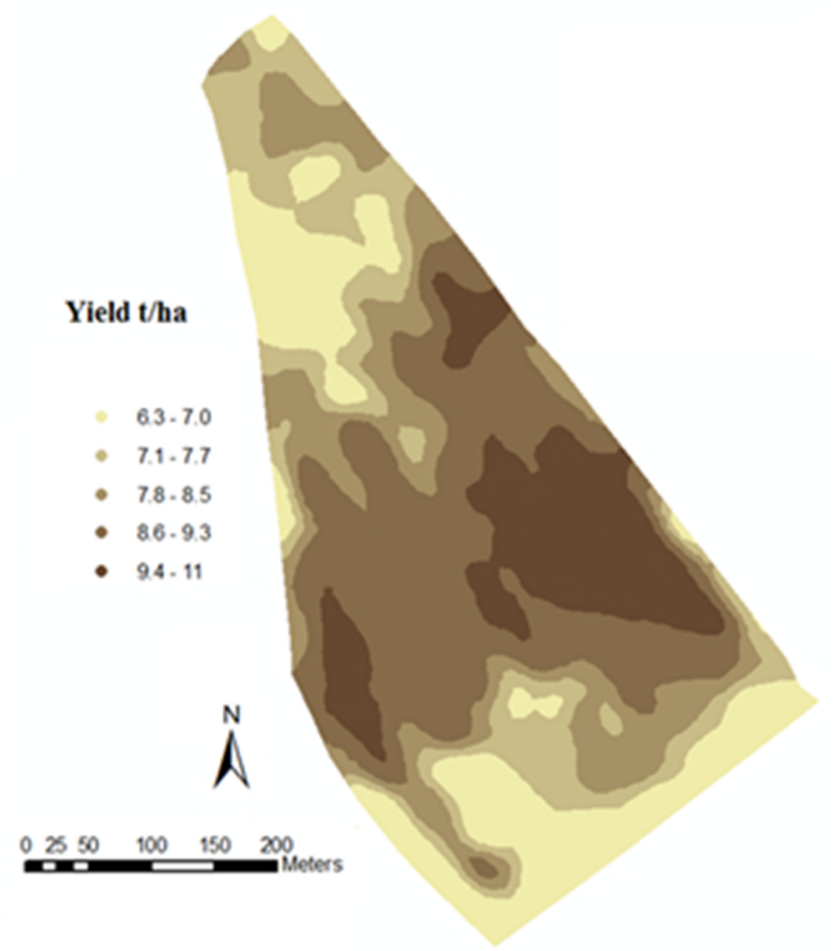

Figure 4: Yield map of wheat measured in September 2015.

\section{2 $\mathrm{K}$-means clusters}

The $k$-means clustering carried out for 1) SH, (Figure 5a) 2) T1 and T2 VRFAs (Figure 5b) and 3) T3 VRFA resulted in different numbers of clusters (Figure 5c). For SH, where on-line predicted FHB and late yellow rust were included in the analysis, the $k$-means clustering resulted in two classes (Figure 5a). Cluster 1 (Figure 5a) demonstrated high normalised means associated with high yellow rust and FHB spread, whereas cluster 2 associated with lower spread of both diseases. Therefore, there is a straightforward classification of wheat yield into high quality and low quality, associated with the cluster 2 and cluster 1, respectively. This classification is made based on the assumption that FHB presence relates to mycotoxin accumulation, resulting in downgrade of grain quality and economic loss (Parry et al., 1995). Yellow rust was included in the classification, as infection reduces yield quantity but also yield 
quality due to affected grain filling. Yield losses in wheat from yellow rust infections are usually the result of reduced kernel number per ear and low weight (Prescott et al., 1986). Small grains are associated with low flour extraction rates (during milling), and low energy contents for livestock feed (Gooding and Davies 1997; Rose et al., 2001). Grain protein content is often reduced with infection by rust (Dimmock and Gooding, 2002). A higher protein content in the grain can fetch higher prices (Devadas et al., 2014).

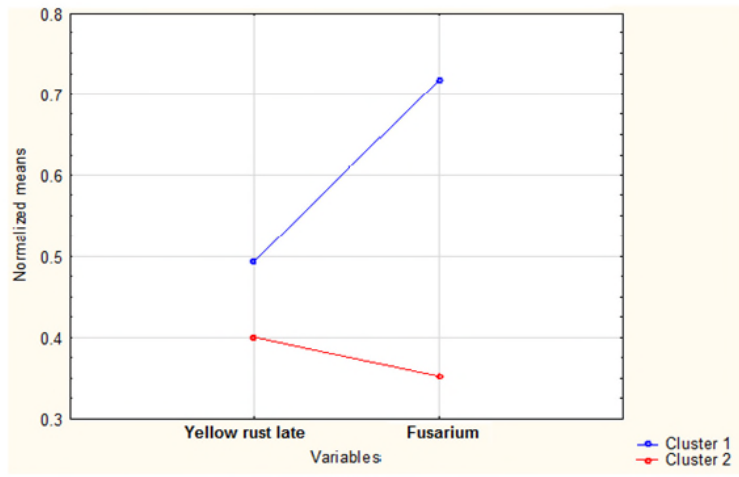

a)

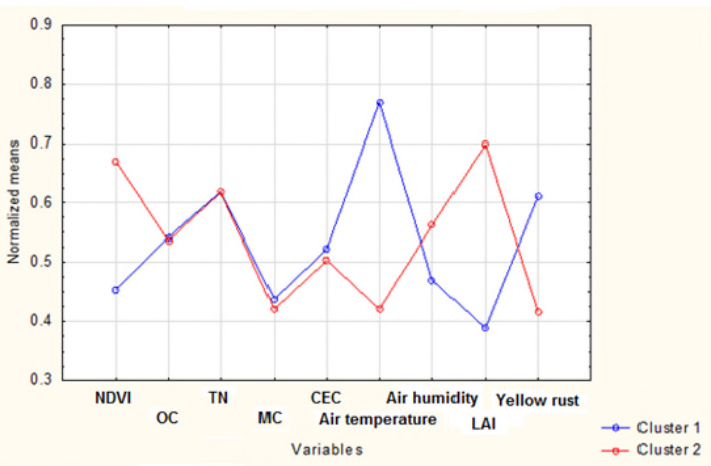

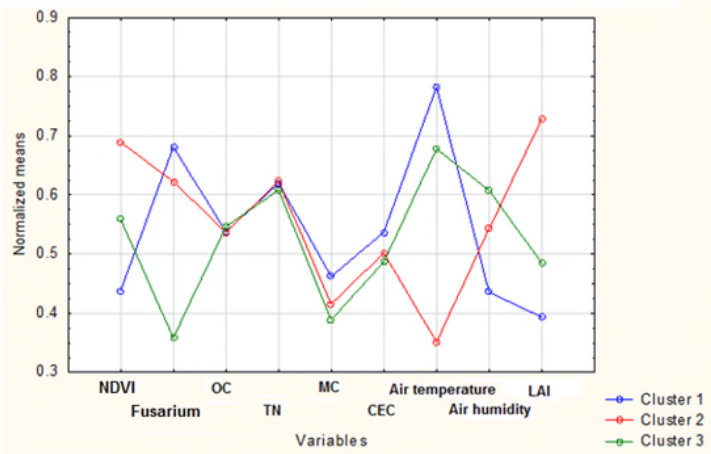

c)

Figure 5: $K$-means cluster analysis for the selective harvest $(\mathrm{SH})$, and the variable rate fungicide application (VRFA). SH (chart a) shows two classes, which are based on the on-line measured late yellow rust and fusarium head blight (FHB). VRFA at the T1 and T2 (chart b) and T3 (chart c) application timings are both based on the measured; normalised difference vegetation index (NDVI), air temperature, air humidity, leaf area index (LAI), and on-line predicted soil organic carbon (OC), total nitrogen (TN), moisture content (MC) and cation exchange capacity (CEC). 
The $k$-means cluster analysis for T1 and T2 VRFAs used; the on-line predicted properties of early yellow rust and the four soil properties, NDVI, LAI, temperature and humidity which produced two clusters (Figure 5b), highly and poorly infected. In cluster 1, high yellow rust is associated with low NDVI and LAI, indicating degraded crop growth (Figure 5b). A smaller crop density (smaller LAI and NDVI) could permit a greater penetration and distribution of the yellow rust spores (Whetton et al., 2018b). However, moisture is essential for yellow rust infection. Yellow rust is most likely to occur in areas with a cool and moist environment during the growing season, with the optimum temperature for urediniospore germination being between 7 and $12^{\circ} \mathrm{C}$ (Chen et al., 2014). A denser canopy is more likely to maintain a higher humidity, but to heat up and cool down slower compared to a sparse canopy (Dammer, 2003). The cluster analysis demonstrates no influences of the on-line predicted soil properties, as no clear differences in the normalised mean values for the four soil properties can be observed between the two clusters. This is expected due to the small variability measured throughout the field area. Due to the higher yellow rust spread of cluster 1, a high fungicide application rate would be proposed, whereas a low application rate would be proposed for cluster 2 .

The $k$-means cluster analysis for T3 VRFA results in three clusters (Figure 5c). Similar to that for T1 and T2 growing stages and due to the small spatial variability range, the effect of online predicted soil properties on FHB spread is negligible. The lower LAI and NDVI (lower crop density) of cluster 1 is associate with higher air temperature and lower air humidity than those of clusters 2 and 3. This has resulted in cluster 1 having the largest FHB pressure and this in turn negatively affected crop growth indicated by low NDVI and LAI. The clear majority of cluster 2 areas are along the edge of the field, where it is understood that there is a higher risk of inoculation, due to the hedgerow (Jenkinson and Parry, 1994; Imathiu et al., 2013). Due to the degree of FHB pressure, clusters, 1, 2 and 3 have been classified at the highest, medium 
and lowest risks for FHB severity. Whilst soil properties have had little influence on crop disease severity in this study, it is suggested to continue monitoring in future, particularly in fields with high variability in soil properties.

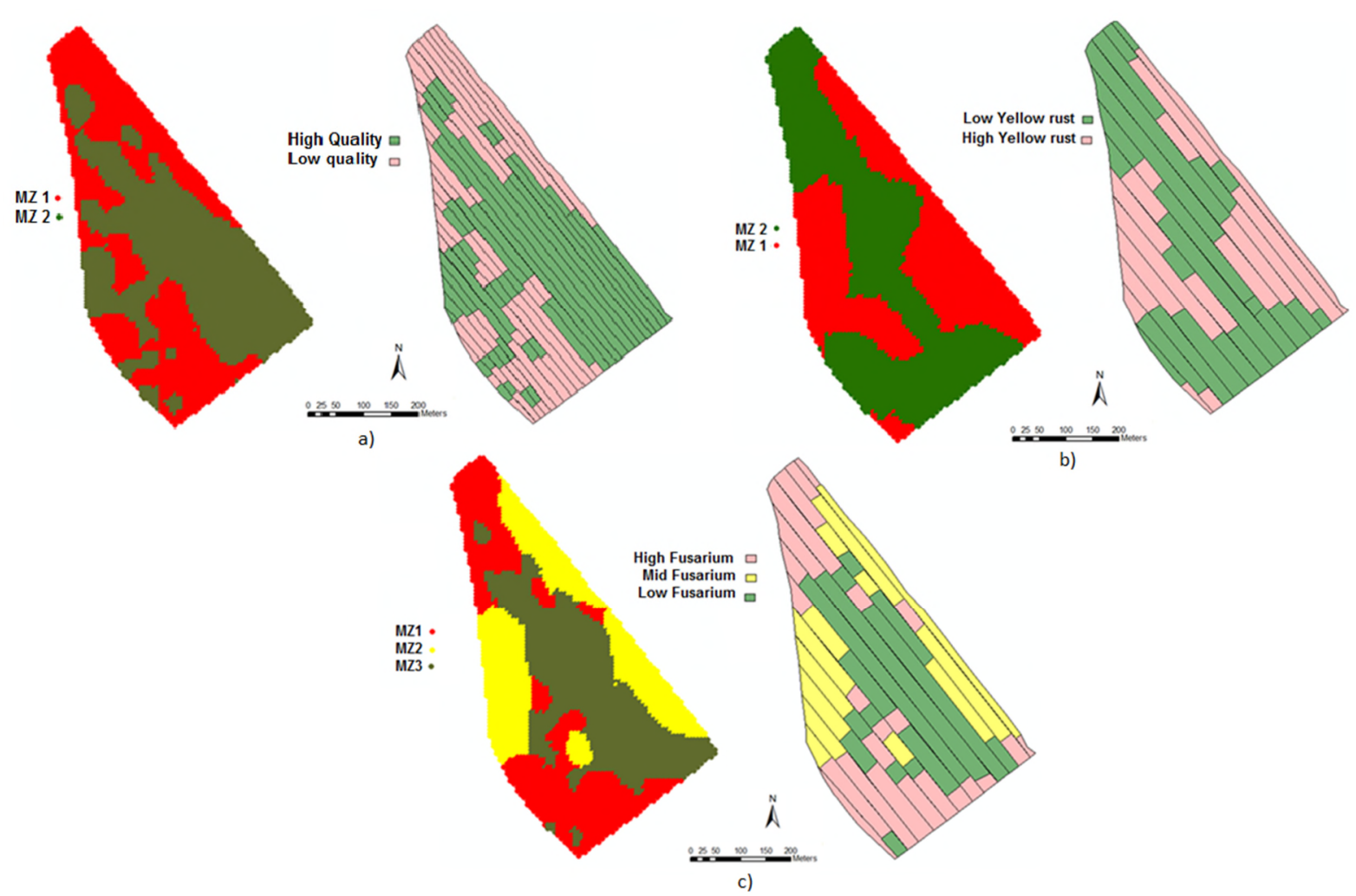

Figure 6: Shows the management zone (MZ) maps for selective harvest (SH) (a) and for variable rate fungicide application (VRFA) (b and c), all obtained by $k$-means clustering. a) The map on the left shows high disease infection (MZ 1) and low disease infection (MZ 2), The map on the right shows high and low quality grain zones, with the field being split into plots of $12 \mathrm{~m}$ wide to match the combine harvest cutting head. b) The map on the left shows low yellow rust (MZ1) and high yellow rust (MZ2), whereas the map on the right shows high and low infection zones, with the field being split into plots of $24 \mathrm{~m}$ to match the sprayer boom width. c) The map on the left shows high fusarium head blight (FHB) (MZ 1), medium FHB (MZ 2), and high FHB (MZ3), whereas the map on the right shows high and low infection zones, with the field being split into plots of $24 \mathrm{~m}$. 


\subsection{Treatment maps}

$\mathrm{MZ}$ maps for the SH developed by $k$-means cluster analysis using on-line predicted late yellow rust and FHB show two distinctive MZs (Figure 5a and Figure 6a). Based on this MZ map, the field was divided into experimental plots of $12 \mathrm{~m}$ width to match the width of the cutting head of a combine harvester, which would be used for SH. The owner of the study farm had witnessed an increase in levels of mycotoxin in recent years. Therefore, a variable harvest will reduce economic loss and increase efficiency by separating the harvested wheat grain into two categories of high and low quality and selling it separately. This SH would also reduce the mycotoxin levels in grain and toxic influences on human health. MZ1 (Figure 6a) is associated with cluster 1 in Figure 5a, with high FHB presence and high risk for mycotoxin presence and toxic effects on human health, whereas MZ 2 is associated with cluster 2, low risk of mycotoxin presence and higher quality grain.

Figure $6 \mathrm{~b}$ and Figure $6 \mathrm{c}$ illustrate spatial distribution of MZs and the division of the field area into $24 \mathrm{~m}$ width plots, responding to a fungicide sprayer boom width of $12 \mathrm{~m}$ either side of a tramline. West et al. (2003) discussed the highest benefit to VRFAs can be achieved with a boom containing separately controllable sections. However, at the commercial farm this technology was not available, so the VRFA maps were based on 24 m widths (with the standard being $12 \mathrm{~m}$ on either side). MZ 2 in Figure 6b, associated with cluster 2 in Figure 5b indicates low disease in the centre, whereas MZ 1 at the field hedges, linked with cluster 1 refers to high yellow rust infections. It's proposed that this MZ map is adopted for VRFA for T1 and T2 growing stages. The MZ map (Figure 6c) for VRFA for the T3 application stage shows three MZs of high (northern and southern edge areas), medium (east and west edge areas) and low (central areas) FHB spread, associated with cluster 1, cluster 2 and cluster 3, respectively 
(Figure 5c). The general shape of the MZ map here (Figure 6c) is like the one developed for yellow rust for $\mathrm{T} 1$ and $\mathrm{T} 2$ application times (Figure 6b), but the former is in three MZs while the latter is in two.

\subsection{Economic benefits}

Table 3 summarises the yield and average disease development in each MZ. For SH, MZ 2 (higher quality grain shown in Figure 6a) is associated with a higher average yield $\left(8.2\right.$ tha $\left.^{-1}\right)$ and lower average late yellow rust (1.9) and FHB (0.54), as compared to MZ 1 (6.9 tha ${ }^{-1}, 2.9$ and 0.87 , respectively). Similarly, for VRFA at T1 and T2 growing stages, MZ 2 (lower early yellow rust pressure shown in Figure $6 \mathrm{~b})$ is associated with higher average yield $\left(8.3\right.$ tha $\left.^{-1}\right)$ and lower early yellow rust pressure (1.2), as compared to MZ 1 (6.7 tha ${ }^{-1}$ and 2.2, respectively). For VRFA at the T3 growing stage, the MZ 3 (lowest FHB pressure as shown in Figure 6c) has the highest average yield $\left(8.3\right.$ tha $\left.^{-1}\right)$ and lowest FHB (0.54), followed by MZ 2 and MZ 1, respectively (Table 3). The consistent link between the yield and disease pressure in the three studied cases proves the correct classification of the field area into proposed MZs, so that MZs with high disease pressure are associated with low yield and vice versa.

The cost-benefit analysis of SH based on the two MZs proposed in this work (Table 4) reveals a gross saving of $£ 519$ per field ( $\left.£ 48.05 \mathrm{ha}^{-1}\right)$, as compared to the homogeneous harvest of the entire field area. This is because of the higher price that the SH could provide for almost $59 \%$ of the field area with high quality of grains (FWI, 2016) harvested from MZ2 with low FHB spread with low mycotoxin concentration.

Table 3: Statistics of yield and disease pressure (fusarium head blight (FHB), early and late yellow rust (YR)) of each management zone (MZ), for the variable rate fungicide applications (VRFA) at growing stage $\mathrm{T} 1$ and $\mathrm{T} 2$ (which consider soil properties, canopy properties and 
early yellow rust); at growing stage T3 (which consider soil properties, canopy properties, and FHB); and for the selective harvest (SH) (late yellow rust and FHB). For the VR T1 and T2 applications, two MZs are considered; MZ1 (high yellow rust disease) and MZ2 (low yellow rust disease). For the VR T3 applications, three MZs are considered; MZ1 (high FHB disease), MZ2 (medium FHB disease) and MZ3 (low FHB disease). SH considers two MZs; MZ1 (lower quality crop) and MZ2 (higher quality crop).

\begin{tabular}{|l|l|l|l|l|l|l|l|}
\hline & MZ & $\begin{array}{l}\text { Total } \\
\text { cluster } \\
\text { area, ha }\end{array}$ & $\begin{array}{l}\text { Total } \\
\text { yield, t }\end{array}$ & $\begin{array}{l}\text { Average } \\
\text { Yield, } \\
\text { tha-1 }^{-1}\end{array}$ & $\begin{array}{l}\text { Average } \\
\text { early YR }\end{array}$ & $\begin{array}{l}\text { Average } \\
\text { late YR }\end{array}$ & $\begin{array}{l}\text { Average } \\
\text { FHB }\end{array}$ \\
\hline \multirow{2}{*}{ SH } & MZ1 & 4.5 & 33.2 & 6.9 & NA & 2.9 & 0.87 \\
\cline { 2 - 8 } & MZ2 & 6.3 & 51.9 & 8.2 & NA & 1.9 & 0.54 \\
\hline \multirow{2}{*}{\begin{tabular}{l} 
V2 T1 \\
\cline { 2 - 8 }
\end{tabular}} & MZ1 & 4.8 & 36.5 & 7.6 & 2.2 & NA & NA \\
\hline \multirow{2}{*}{ VR T3 } & MZ1 & 3.6 & 26.3 & 7.3 & NA & NA & 0.8 \\
\cline { 2 - 8 } & MZ2 & 3.2 & 25.9 & 8.1 & NA & NA & 0.71 \\
\cline { 2 - 8 } & MZ3 & 4 & 33.2 & 8.3 & NA & NA & 0.54 \\
\hline
\end{tabular}

VRFA at the T1 and T2 application times are associated with BBCH growth stage 31-33 and 37-39, respectively. They are aimed at protecting the third, second, and flag leaves from foliar diseases, such as yellow rust. In this study, VRFA is split into two areas of high and low disease pressure as compared to a homogenous rate application applied as the full dose. The calculated potential gross saving of the VRFA at the T1 and T2 was $£ 95.04$ per application for this field ( $£ 190.08$ for the T1 and T2 applications), with an average gross saving of $£ 8.8$ per ha per 
application (or $£ 17.6$ for two applications) (Table 5), compared with the homogeneous application. This assumes that yellow rust has a direct link with grain yield and reducing the fungicide dosage on lower yellow rust infected areas would not have significant negative impacts on yield. The homogenous rate would consume 7.7761 fungicide (Proline 275) per application for the 10.8 ha field, whereas the variable rate would need 6.048 , suggesting a potential reduction of 1.731 per application (or 3.461 for the two applications). This reduction would sum up to a $22.24 \%$ reduction in fungicide application by adopting the variable application method, as compared to the homogeneous application. Estimates for the carbon contribution for the production of fungicide applied in conventional farming system of wheat per hectare in the UK are $3.30 \mathrm{~kg} \mathrm{CO} 2-\mathrm{e} \mathrm{kg}^{-1}$. However, effective use of fungicides is associated to a carbon saving (Hughes et al., 2011; Lin et al., 2011).

The VRFA at the T3 application stage is usually an ear wash aimed at preserving grain quality from diseases such as FHB. This application in the study field would be based on 3 rates according to the three $\mathrm{MZ}$ delineated by the $k$-means clustering. Treatments proposed are: full dose for the heavily infected MZ1, 75\% dose for the medium infected MZ2 and 50\% dose for the low infected MZ3, compared to the full dose rate for the homogenous application proposed for the entire field area. The per field potential gross saving of the VRFA at the T3 application time (targeted at BBCH growth stage 52-60) is $£ 191.2$, with an average saving of $£ 17.7 \mathrm{ha}^{-1}$ (Table 5). The homogenous rate would consume 21.61 fungicide (Adexar) per 10.8 ha total field area, whereas the VRFA would consume 161 , with a potential reduction of 5.61 per application, or $25.93 \%$ to be expected by adopting the VRFA, as compared to the uniform application.

By combining he $\mathrm{SH}$ with the VRFA at $\mathrm{T} 1$ and $\mathrm{T} 2$ and at $\mathrm{T} 3$ application times, a potential gross saving of $£ 900.18$ is expected for this field, which is an average gross saving of $£ 83.35$ per ha. 
It is possible to consider the combined economic benefit as $\mathrm{SH}$ results in savings from preventing down grading of the grain, whilst VRFAs results in savings from reducing fungicide applied compared to $100 \%$ full homogenous rate. Since the commercial price of implementing soil sensing and crop sensing in the UK are $£ 10 \mathrm{ha}^{-1}$ and $£ 6.5 \mathrm{ha}^{-1}$, this would leave a total saving of $£ 721.98$ per year for the field, or $£ 66.84 \mathrm{ha}^{-1}$.

The current technology of fungal disease treatment based on the CROP-meter offers economic benefits by just reducing fungicide input but does not necessarily increase crop quality or quantity (Ehlert et al., 2003). The suggested methodology in the current work may lead to not only economic, but environmental and social benefits. The potential reduction in the amount of fungicide applied (Table 5) would also lead to reducing the environmental impact due to reduced soil and water contamination, and overall reduction in GHG by increasing crop yield and cultivated field area efficiency. The social benefit is associated with lower mycotoxin concentration's in human consumed grain obtained with SH. If a field has generally a low disease spread, and the farmer would otherwise prescribe a half dose for the field, they can add a full dose in the areas recognised to be at higher risk. Better control of the disease (by applying higher rates on risk areas than lower rates homogenously), and reducing the chance of the efficacy of the fungicide product being reduced in the long term, as fungal strains adapt and develop increased immunity (FRAC, 2010).

The current work assesses the use of high spatial resolution data to compare the economic and environmental benefit of a VRFA and SH to a conventional homogenous practice. Whilst the study found an economic gross saving of $£ 83.35 \mathrm{ha}^{-1}$ and an actual saving of $£ 66.84 \mathrm{ha}^{-1}$, the results are specific to this field, crop and year. For a decision tool that would recommend a time of spraying and VRFA, further components would need to be considered such as the use of air sampling for the detection of airborne pathogens. West et al. (2008) combined air 
sampling with polymerase chain reaction analysis, for the quantitative identification of pathogens. A process-based model which included climate data would create a robust decision tool to help optimise decisions relating to fungicide applications. In conventional farming, fungicides are often applied in response to agronomists' visual assessments. This study has highlighted the potential economic benefit of the disease mapping methodology for VRFA and SH in a non-uniform field, compared to conventional methods. However, further work should consider a combination of disease mapping, pathogen sensor technologies, and temporal data (such as plant growth, and climate data) in a process-based model, for production of a robust decision tool. The SH could potentially develop to having separate grain tanks at harvest, but confidence in the concept would need to be established before such infrastructure could be developed. However, it is important to acknowledge that SH and VRFA approaches are only appropriate for heterogeneous fields, where significant variations of disease levels are witnessed in different areas of a field. The approaches would be redundant in homogenous fields.

\section{Conclusions}

The study proposed the use of management zones for variable rate fungicide applications (VRFA) and selective harvest (SH) of crops. The study site was in a winter wheat crop infected with yellow rust and fusarium. A $k$-means cluster analysis was implemented to divide the experimental field into separated clusters (zones) based on on-line predicted fusarium and yellow rust (measured with a hyperspectral imager), on-line predicted soil total nitrogen (TN), organic carbon (OC), moisture content (MC) and cation exchange capacity (CEC) (measured with an on-line visible and near infrared (vis-NIR) spectroscopy sensor), measured crop canopy 
normalised difference vegetation index (NDVI) and leaf area index (LAI), yield, and air humidity and temperature. The main findings highlight the following conclusions;

1) The field area could be divided into different management zones for each of the VRFA applications and $\mathrm{SH}$, using K-means clustering and different input data. Management zones with high disease pressure were associated with low NDVI and LAI, and high air temperature and the opposite was true for management zones with low disease pressure.

2) Fungicide reductions of $22.24 \%$ (for $\mathrm{T} 1$ and $\mathrm{T} 2$ applications) and $25.93 \%$ (for $\mathrm{T} 3$ application) were calculated for the entire 10.8 ha field for VRFA, as compared to homogeneous application.

3) The SH of the high and low-quality grain categories would result in a reduced risk of mycotoxin contaminated grain reaching a human consumer.

4) The gross profit of SH and VRFA was $£ 83.35 \mathrm{ha}^{-1}$, divided into $£ 48.04 \mathrm{ha}^{-1}$ for $\mathrm{SH}$, $£ 8.8 \mathrm{ha}^{-1}$ for each VRFA at T1 and T2 applications and $£ 17.7 \mathrm{ha}^{-1}$ at T3 application. The net saving after considering sensing costs is $£ 66.84 \mathrm{ha}^{-1}$, which is roughly equivalent to $€ 80$ or $\$ 90 \mathrm{ha}^{-1}$ per year.

The results highlighted here are specific to one field with specific circumstances. The study demonstrates the potential benefits in applying VRFA and SH to variable disease distributions. Future work should focus on the implementation of the proposed methodology in a larger number of fields. The cost-benefit analysis could be expanded to account for yield responses to different fungicide application rates, which was not included in the current work.

\section{Acknowledgement}

We acknowledge the funding received for FarmFUSE project from the ICT-AGRI under the European Commission's ERA-NET scheme under the 7th Framework Programme, and the UK 
Department of Environment, Food and Rural Affairs (contract no: IF0208). The corresponding author acknowledges the FWO funded Odysseus SiTeMan Project (Nr. G0F9216N).

\section{References}

Berry, P. M., Kindred, D. R., Olesen, J. E., Jorgensen, L. N., \& Paveley, N. D. (2010). Quantifying the effect of interactions between disease control, nitrogen supply and land use change on the greenhouse gas emissions associated with wheat production. Plant Pathology, $59,753-763$.

Bryson, R., Paveley, N., Clark, W., Sylvester-Bradley, R., and Scott, R. (1997). Use of in-field measurements of green leaf area and incident radiation to estimate the effects of yellow rust epidemics on the yield of winter wheat. European Journal of Agronomy, 7, pp. 53-62

Burney, J. A., Davis, S. J., \& Lobell, D. B. (2010). Greenhouse gas mitigation by agricultural intensification. Proceedings of the National Academy of Science, 26, 12052-12057.

Cambardella, C.A., Moorman, T.B., Parkin, T.B., Karlen, D.L., Novak, J.M., Turco, R.F.\& Konopka, A.E. 1994. Field-Scale Variability of Soil Properties in Central Iowa. Soil Science Society of America Journal 58, 1501-1511.

Carlton, R., Berry, P., \& Smith, P. (2010). Impact of crop yield reduction on greenhouse gas emissions from compensatory cultivation of pasture and forested land. International Journal of Agricultural Sustainability, 8, 164-175.

Chang, D., Zhang, J., Zhu, L., Ge, S.-H., Li, P.-Y.\& Liu, G.-S. (2014). Delineation of management zones using an active canopy sensor for a tobacco field. Computers and Electronics in Agriculture, 109, pp. 172-178. 
Chen, X. M. (2005). Epidemiology and control of stripe rust (Puccinia striiformis f. sp. tritici) on wheat. Canadian Pathology, 27, pp. 314-337.

Chen, W., Wellings, C., Chen, X., Kang, Z. and Liu, T., (2014). Wheat stripe (yellow) rust caused by Puccinia striiformis f. sp. tritici. Molecular plant pathology, 15(5), pp.433-446.

Clark, B., (2016) FWI, Fungicide management: timings, Farmers Academy, available at http://www.fwi.co.uk/academy/lesson/fungicide-management-timings. (Accessed: 10th November 2016).

Dammer, K.-H. (2003). In: Investigations into the dynamic of climatic parameters and infections with fungi diseases in heterogeneous cereal stands (p. 23). Potsdam, Germany: Jahresbericht des ATB.

Devadas, R., Simpfendorfer, S., Backhouse, D. and Lamb, D.W., (2014). Effect of stripe rust on the yield response of wheat to nitrogen. The Crop Journal, 2(4), pp.201-206.

Dimmock, J.P.R.E. and Gooding, M.J., (2002). The influence of foliar diseases, and their control by fungicides, on the protein concentration in wheat grain: a review. The Journal of Agricultural Science, 138(04), pp.349-366

Doling, D.A. and Doodson, J.K., (1968). The effect of yellow rust on the yield of spring and winter wheat. Transactions of the British Mycological Society, 51(3), pp. 427-434

Doodson, J.K., Manners, J.G. and Myers, A., (1964). Some effects of yellow rust (Puccinia striiformis) on the growth and yield of a spring wheat. Annals of Botany, 28(3), pp. 459-472.

Dordas, C., 2009. Role of nutrients in controlling plant diseases in sustainable agriculture: a review. In Sustainable agriculture (pp. 443-460). Springer, Dordrecht. 
Ehlert, D., Hammen, V., \& Adamek, R. (2003). online sensor pendulum-meter for determination of plant mass. Precision Agriculture, 4, pp. 139-148.

Fungicide Resistance Action Committee, (2010). FRAC Recommendations for Fungicide FWI (2016) Market prices Arable, Available at: http://www.fwi.co.uk/business/prices-trends/ (Accessed: 10th November 2016).

Gooding, M.J. and Davies, W.P., (1997). Wheat production and utilization: systems, quality and the environment. CAB international.

Graham, R. D. and M. J. Webb. (1991). Micronutirents and disease resistance and tolerance in plants. pp. 329-370.

Gustavsson, J., Cederberg, C., Sonesson, U., Van Otterdijk, R. and Meybeck, A., (2011). Global food losses and food waste (pp. 1-38). Rome: FAO.

Herrera-Foessel, S.A., Singh, R.P., Huerta-Espino, J., Crossa, J., Yuen, J. and Djurle, A., (2006). Effect of leaf rust on grain yield and yield traits of durum wheats with race-specific and slow-rusting resistance to leaf rust. Plant Disease, 90(8), pp.1065-1072.

Hole, D., Perkins, A., Wilson, J. D., Alexander, I. H., Grice, P. V., \& Evans, A. (2005). Does organic farming benefit biodiversity? Biological Conservation, 122, pp. 113-130.

Huber, D. M. (1980). The role of mineral nutrition in defense. pp. 381-406. In: J. G. Horsfall and E. B. Cowling (eds.), Plant Pathology An Advanced Treati. Academic Press, New York, NY. 
Hughes, D. J., West, J. S., Atkins, S. D., Gladders, P, Jeger, M. J. \& Fitt, B. D. L. (2011). Effects of disease control by fungicides on Greenhouse Gas (GHG) emissions by UK arable crop production. Pest Management Science, 67, 1082-1092.

Imathiu, S.M., Edwards, S.G., Ray, R.V. and Back, M.A. (2013). Fusarium langsethiae-a HT2 and T- 2 Toxins Producer that Needs More Attention. Journal of Phytopathology, 161(1), pp. $1-10$

Jelinek CF, Pohland AE, Wood GE. (1989) Worldwide occurrence of mycotoxins in foods and feeds-An update. J AOAC Int, 72, pp. 223-230.

Jenkinson, P. and Parry, D.W. (1994). Splash dispersal of conidia of Fusarium culmorum and Fusarium avenaceum. Mycological Research, 98(5), pp.506-510.

Kuang, \& Mouazen, A. M. (2013). Non-biased prediction of soil organic carbon and total nitrogen with vis-NIR spectroscopy, as affected by soil moisture content and texture. Biosystems Engineering, 114(3), pp. 249-258.

Kuang, B., Mahmood, H. S., Quraishi, Z., Hoogmoed, W., Mouazen, A., \& van Henten, E. J. (2012). Sensing soil properties in the laboratory, in situ, and on-line: a review. In Donald Sparks, editors: Advances in Agronomy pp. 155-224. 114, AGRON, UK: Academic Press.

Lancashire, P.D., Bleiholder, H., Boom, T.V.D., Langelüddeke, P., Stauss, R., WEBER, E. and Witzenberger, A., (1991). A uniform decimal code for growth stages of crops and weeds. Annals of applied Biology, 119(3), pp.561-601.

Lin, B. B., Chappell, M. J., Vandermeer, J., Smith, G., Quintero, E., Bezner-Kerr, R., et al. (2011). Effects of industrial agriculture on climate change and the mitigation potential of small- 
scale agro-ecological farms. CAB Reviews: Perspectives in Agriculture, Veterinary Science, Nutrition and Natural Resources, 6, 1-18.

Livingston, D.P., Tuong, T.D., Isleib, T.G. and Murphy, J.P., 2016. Differences between wheat genotypes in damage from freezing temperatures during reproductive growth. European Journal of Agronomy, 74, pp.164-172.

MacQueen, J., (1967), June. Some methods for classification and analysis of multivariate observations. In Proceedings of the fifth Berkeley symposium on mathematical statistics and probability (Vol. 1, No. 14, pp. 281-297).

Mahmuti, M., West, J. S., Watts, J., Gladders, P., \& Fitt, B. D. L. (2009). Controlling crop disease contributes to both food security and climate change mitigation. International Journal of Agricultural Sustainability, 7, 189-202.

Marin-González, O., Kuang, B., Quraishi, M., Munoz-Garcia, M., \& Mouazen, A. (2013). online measurement of soil properties without direct spectral response in near infrared spectral range. Soil \& Tillage Research, 132, pp. 21-29.

Mkhabela, M., Bullock, P., Raj, S., Wang, S., \& Yang, Y. (2011). Crop yield forecasting on the Canadian Prairies using MODIS NDVI data. Agricultural and Forest Meteorology, 151(3), pp. 385-393.

Mouazen, A. M. (2006). Soil Survey Device. International publication published under the patent cooperation treaty (PCT). World Intellectual Property Organization, International Bureau. International Publication Number: WO2006/015463; PCT/BE2005/000129; IPC: G01N21/00; G01N21/00. 
Mouazen, A., De Baerdemaeker, J. \& Ramon, H., (2006). Effect of wavelength range on the measurement accuracy of some selected soil constituents using visual-near infrared spectroscopy. Journal of Near Infrared Spectroscopy, Volume 14, pp. 189-199.

Oerke, E.C., (2006). Crop losses to pests. The Journal of Agricultural Science, 144(1), pp.3143.

Parry DW, Jenkinson P, McLead L. (1995). Fusarium ear blight (scab) in small grain cerealsa review. Plant Pathol 44, pp. 207-238

Paul, P.A., Lipps, P.E. and Madden, L.V., (2005). Relationship between visual estimates of Fusarium head blight intensity and deoxynivalenol accumulation in harvested wheat grain: A meta-analysis. Phytopathology, 95(10), pp.1225-1236.

Pimentel, D., Harvey, C., Resosudarmo, P., Sinclair, K., Kurz, D., McNair, M., Crist, S., Shpritz, L., Fitton, L., Saffouri, R. and Blair, R., (1995). Environmental and economic costs of soil erosion and conservation benefits. Science-AAAS-Weekly Paper Edition, 267(5201), pp.1117-1122.

Prescott, J.M., (1986). Enfermedades y plagas del trigo: una guía para su identificación en el campo. CIMMYT.

Rose, S.P., Pirgozliev, V.R., McCracken, K.J., McNab, J.M. and Miller, H.M., (2001). Specific weight and quality measurements on the nutritional value of four wheat cultivars for broiler chickens. ASPECTS OF APPLIED BIOLOGY, 64, pp.85-86.

Rozalski, K., Pudelko, J., and Skrzypczak, G. (1998). Disease incidence in winter wheat and spring triticale as influenced by crop protection and nitrogen. Progress in Plant Protection, 38, pp. S.551-S.554. 
Safavi, S.A., (2015). Effects of yellow rust on yield of race-specific and slow rusting resistant wheat genotypes. Journal of Crop Protection, 4(3), pp.395-408.

Sasaki, Y., Okamoto, T., Imou, K., \& Torii, T. (1999). Generating of Distinction Parameter for Automatic Diagnosis of Plant Disease by GP. Journal of the Japanese Society of Agricultural Machinery, 61, 73-80 (in Japanese)

Snoeijers, S.S., Pérez-García, A., Joosten, M.H. and De Wit, P.J., (2000). The effect of nitrogen on disease development and gene expression in bacterial and fungal plant pathogens. European Journal of Plant Pathology,106(6), pp.493-506.

Stokes, D.T., Sylvester-Bradley, R., Clare, R., Scott, R.K., Hopkinson, J., Milford, G.F.J. and Salmon, S.E., 1998. An integrated approach to nitrogen nutrition for wheat. HGCA Project Report (United Kingdom).

Sylvester-Bradley R., Kindred D. (2009). Analysing nitrogen responses of cereals to prioritise routes to the improvement of nitrogen use efficiency. Journal of Experimental Botany, 60, pp. $1939-51$.

Thomas, S., Wahabzada, M., Kuska, M.T., Rascher, U. and Mahlein, A.K., (2017). Observation of plant-pathogen interaction by simultaneous hyperspectral imaging reflection and transmission measurements. Functional Plant Biology, 44(1), pp.23-34.

West, J.S., Bravo, C., Oberti, R., Lemaire, D., Moshou, D. and McCartney, H.A., (2003). The potential of optical canopy measurement for targeted control of field crop diseases. Annual review of Phytopathology, 41(1), pp.593-614.

West, J.S., Atkins, S.D., Emberlin, J. and Fitt, B.D., 2008. PCR to predict risk of airborne disease. Trends in microbiology, 16(8), pp.380-387. 
Whetton, R.L., Waine, T.W. and Mouazen, A.M., (2017). Optimising configuration of a hyperspectral imager for on-line field measurement of wheat canopy. Biosystems Engineering, 155, pp.84-95.

Whetton, R.L., Hassall, K.L., Waine, T.W. and Mouazen, A.M. (2018a). Hyperspectral measurements of yellow rust and fusarium in cereal crops: Part 1: Laboratory measurement. Biosystems Engineering, 166: 101-115.

Whetton, R.L., Waine, T.W. and Mouazen, A.M., 2018. Hyperspectral measurements of yellow rust and fusarium head blight in cereal crops: Part 2: On-line field measurement. Biosystems engineering, 167, pp.144-158. 